\title{
Adherence to guidelines in management of symptoms suggestive of heart failure in primary care
}

\author{
Benedict Hayhoe, ${ }^{1}$ Dani Kim, ${ }^{1,2}$ Paul P Aylin, ${ }^{1,2}$ F Azeem Majeed, ${ }^{1}$ Martin R Cowie, ${ }^{3}$ \\ Alex Bottle 1,2
}

- Additional material is published online only. To view please visit the journal online (http://dx.doi.org/10.1136/ heartjnl-2018-313971).

${ }^{1}$ Department of Primary Care and Public Health, Imperial College London, London, UK ${ }^{2}$ Dr Foster Unit, Department of Primary Care and Public Health, Imperial College London, London, UK

${ }^{3}$ National Heart \& Lung Institute, Imperial College London, London, UK

\section{Correspondence to}

Dr Benedict Hayhoe,

Department of Primary Care and Public Health, Imperial College London, London W6 8RP, UK; b. hayhoe@imperial.ac.uk

Received 3 August 2018 Revised 17 October 2018 Accepted 6 November 2018 Published Online First 4 December 2018

\section{Linked}

- http://dx.doi.org/10.1136/ heartjnl-2018-314396

\section{Check for updates}

(C) Author(s) (or their employer(s)) 2019. No commercial re-use. See rights and permissions. Published by BMJ.

To cite: Hayhoe B, Kim D, Aylin PP, et al. Heart

2019;105:678-685.

\section{ABSTRACT \\ Objective Clinical guidelines on heart failure (HF)} suggest timings for investigation and referral in primary care. We calculated the time for patients to achieve key elements in the recommended pathway to diagnosis of HF.

Methods In this observational study, we used linked primary and secondary care data (Clinical Practice Research Datalink, a database of anonymised electronic records from UK general practices) between 2010 and 2013. Records were examined for presenting symptoms (breathlessness, fatigue, ankle swelling) and key elements of the National Institute for Health and Care Excellence-recommended pathway to diagnosis (serum natriuretic peptide (NP) test, echocardiography, specialist referral).

Results 42403 patients were diagnosed with HF, of whom 16597 presented in primary care with suggestive symptoms. 6464 (39\%) had recorded NP or echocardiography, and 6043 (36\%) specialist referral. Median time from recorded symptom(s) to investigation (NP or echocardiography) was 292 days (IQR 34-844) and to referral 236 days (IQR 42-721). Median time from symptom(s) to diagnosis was 972 days (IQR 337-1468) and to treatment with HF-relevant medication 803 days (IQR 230-1364). Factors significantly affecting timing of referral, treatment and diagnosis included patients' sex $(p=0.001)$, age $(p<0.001)$, deprivation score $(p=0.001)$, comorbidities $(p<0.001)$ and presenting symptom type $(p<0.001)$.

Conclusions Median times to investigation or referral of patients presenting in primary care with symptoms suggestive of HF considerably exceeded recommendations. There is a need to support clinicians in the diagnosis of HF in primary care, with improved access to investigation and specialist assessment to support timely management.

\section{INTRODUCTION}

Heart failure (HF) is a common chronic condition characterised by reduction of the heart's ability to function as a pump. ${ }^{1}$ High morbidity and mortality, with some 26 million people affected worldwide, means that it represents a significant burden on patients and health systems.

Identification of $\mathrm{HF}$ is based on patients presenting with classic symptoms: breathlessness, ankle swelling and fatigue. Evidence exists for serum natriuretic peptide (NP) measurements, either B-type natriuretic peptide (BNP) or $\mathrm{N}$-terminal pro-B-type natriuretic peptide (NTproBNP), as a screening test for symptomatic patients. ${ }^{3}$ However, timely and accurate identification, key to effective management, ${ }^{13}$ remains difficult, ${ }^{45}$ especially in primary care where patients often present. ${ }^{3}$ 6-8 Diagnosis is complicated by symptoms that are not specific for HF, atypical presentations in the elderly, ${ }^{4}$ significant diagnostic overlap with respiratory conditions ${ }^{9}$ and variability in access to key investigations. ${ }^{5}$ Delay in diagnosis and treatment will result in poorer prognosis. ${ }^{310}$

In the UK, the National Institute for Health and Care Excellence (NICE) provides recommendations on investigation and referral of patients with symptoms suggestive of HF in primary care, including strict time limits to promote timely diagnosis and management. These include ${ }^{11}$

1. For patients with a history of myocardial infarction (MI): transthoracic Doppler 2D echocardiography and referral for specialist assessment within 2 weeks.

2. For patients without a history of MI: measurement of serum NP, followed by echocardiography and referral for specialist assessment within 6 weeks for those with a BNP level of $100-400 \mathrm{pg} / \mathrm{mL}$ or NTproBNP $400-2000 \mathrm{pg} /$ $\mathrm{mL}$, or within 2 weeks for those with higher levels, BNP $>400 \mathrm{pg} / \mathrm{mL}$ or NTproBNP>2000 pg/ $\mathrm{mL}$.

Similar recommendations are given in North America (American College of Cardiology/American Heart Association (ACC/AHA) $)^{12}$ and Europe (European Society for Cardiology (ESC)), ${ }^{1}$ although these do not include timings for investigations and assessment.

We have established that few patients with recorded symptoms of HF follow a pathway to diagnosis supported by guidance in primary care. ${ }^{13}$ However, the extent to which NICE-recommended time limits for investigations and referral are adhered to is unclear. We used linked National Health Service (NHS) primary and secondary care data to track patients with HF in England from presentation in primary care with suggestive symptoms, aiming to establish the time within which key aspects of their investigation and management took place.

\section{METHODS}

\section{Data sources}

The Clinical Practice Research Datalink (CPRD) is a database of anonymised electronic records from about $7 \%$ of UK general practices from 1987 to the 
present. ${ }^{14}$ Primary care records are linked nationally to hospital admissions in England (Hospital Episode Statistics (HES)) and the death registry (Office for National Statistics (ONS)). We included data from 2005 to 2014.

\section{Patient cohort}

We used clinical codes to identify key events and characteristics affecting patients within the datasets. We searched for patients with HF diagnosed between 1 January 2010 and 31 March 2013. For each patient, the diagnosis date was taken to be the first coded record of HF, either in the primary care record or in hospital admission data. For the former, we identified primary care consultations and for the latter, hospital admissions for HF using codes by Hawkins et al, ${ }^{15}$ augmented by our clinicians (online supplementary appendix 1). In HES, International Statistical Classification of Diseases, 10th revision, ${ }^{16}$ codes were used.

Exclusions were CPRD records at practices not linked to HES, patients not registered for the whole 10-year period and standard CPRD data quality exclusions (online supplementary appendix 2).

The following characteristics were defined at the time of patients' first symptom: sex, age, deprivation quintile (Index of Multiple Deprivation score 2010), ${ }^{17}$ selected comorbidities (tracking back up to 5 years), symptom type at first presentation (breathlessness only, ankle swelling only, fatigue only or two or more symptoms), and whether patients had another consultation for symptoms within 6 months. Comorbidities from the Charlson set were defined as per Khan $e$ t $a l^{18}$ with some added by our team. ${ }^{13}$ Otherwise, codes were identified using the CPRD medical and product dictionaries.

\section{Time points of interest}

We were interested in timing of key aspects of investigation and management before diagnosis. Consequently, we focused most of our analysis on a subset of patients with HF who presented with symptoms and subsequently had investigation or specialist referral as recommended by NICE. Sets of clinical codes for tests, medications and referrals (online supplementary appendix
1) ${ }^{19} 20$ were used to identify management prior to diagnosis, tracking back 5 years.

Time points of interest were (1) earliest echocardiogram and/or serum natriuretic peptide test; (2) earliest referral to a specialist; (3) earliest HF medication (ACE inhibitor, ARB and HF-specific beta-blocker); and (4) HF diagnosis.

\section{Statistical analysis}

We calculated the times from symptom to investigation, referral or diagnosis and from investigation or referral to medication or diagnosis. Data were summarised using medians (IQR) for all patients and grouped by patient characteristics. For the latter, $\mathrm{p}$ values from Wilcoxon-Mann-Whitney (WMW) tests were used to assess for significance at the 5\% level in categorical variables. Analyses were conducted using SAS V.9.4.

\section{RESULTS}

\section{Patient characteristics}

We identified 42403 patients with a HF diagnosis between 2010 and 2013, of whom 16597 (39\%) presented in primary care with one or more of three key symptoms. Patients without recorded symptoms were included in previous analysis, reported elsewhere. ${ }^{13}$ Of the 16597 patients with HF symptoms, 6464 (39\%) had a recorded serum NP test and/or echocardiogram, and $6043(36 \%)$ a specialist referral. We examined a subset of 8913 patients who had presented with HF symptoms and subsequently had one or more of these key aspects of care, as recommended by NICE. Figure 1 illustrates subsets of patients within our cohort; the characteristics of these included patients $(n=8913)$ are set out in table 1.

Of included patients, $51.5 \%$ were male, and $83 \%$ were 65 years or over. Over half had an existing diagnosis of hypertension (59\%), and one-quarter coronary artery disease (26\%), while atrial fibrillation, diabetes mellitus, chronic pulmonary disease and renal disease each affected about one-fifth of patients $(22 \%$, $20 \%, 23 \%$ and 23\%, respectively). The majority had breathlessness as their only recorded symptom at presentation (70\%), with only $1 \%$ having two or more recorded HF symptoms.

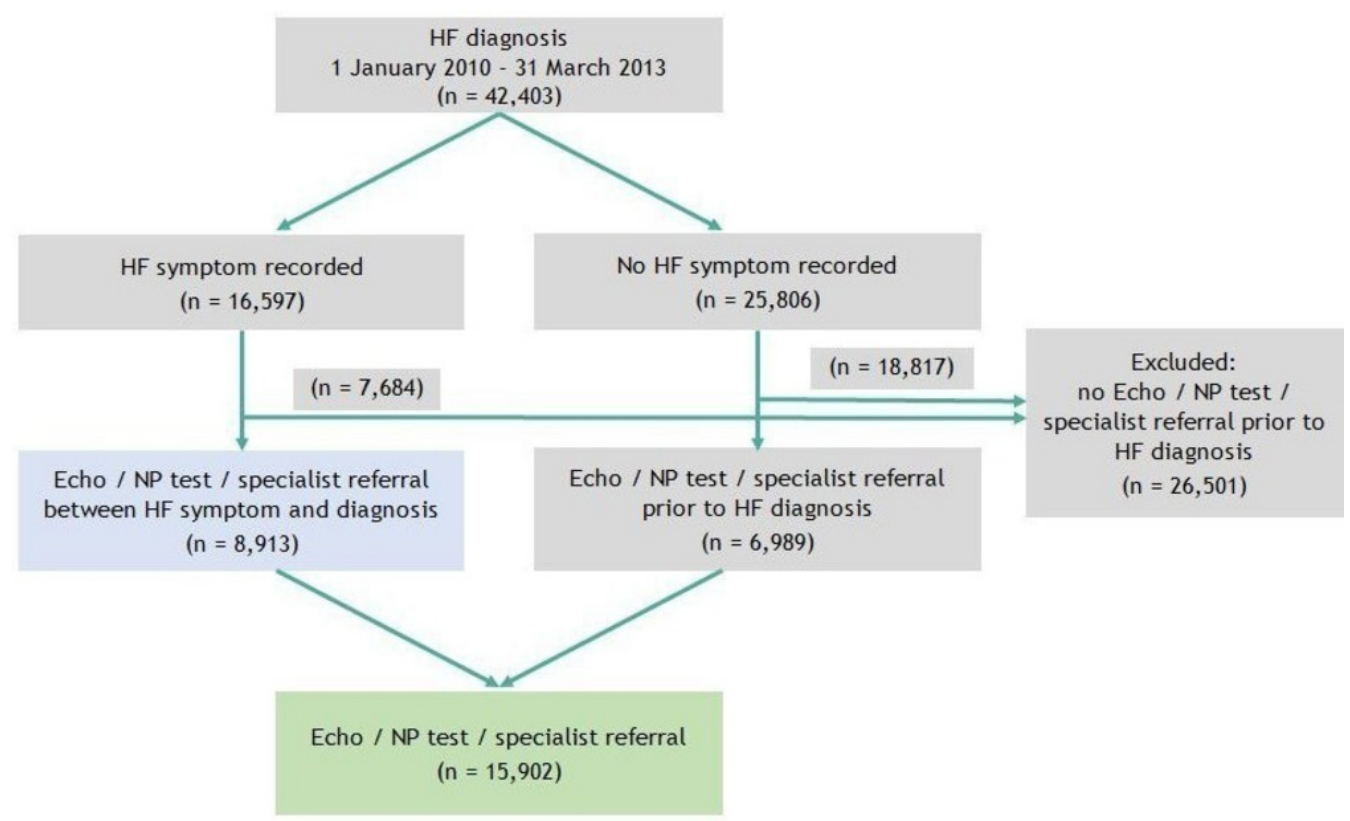

Figure 1 Subgroups within patient cohort. HF, heart failure; NP, natriuretic peptide. 


\begin{tabular}{|c|c|c|}
\hline Variable & Level & $\mathrm{N}(\%)$ \\
\hline \multirow[t]{2}{*}{ Sex } & Male & $4586(51.5)$ \\
\hline & Female & $4327(48.5)$ \\
\hline \multirow[t]{5}{*}{ Age group (years) } & $<45$ & $155(1.7)$ \\
\hline & $45-64$ & $1402(15.7)$ \\
\hline & $65-74$ & $2413(27.1)$ \\
\hline & $75-84$ & $3455(38.8)$ \\
\hline & $85+$ & $1488(16.7)$ \\
\hline \multirow[t]{5}{*}{ IMD quintile } & 1 (least deprived) & $1854(20.8)$ \\
\hline & 2 & $2144(24.1)$ \\
\hline & 3 (average) & $1860(20.9)$ \\
\hline & 4 & $1643(18.4)$ \\
\hline & 5 (most deprived) & $1412(15.8)$ \\
\hline \multirow[t]{2}{*}{ Diagnosis source } & Primary care & $2979(33.4)$ \\
\hline & Hospital & $5934(66.6)$ \\
\hline \multirow[t]{5}{*}{ Comorbidity count } & 0 & $1464(16.4)$ \\
\hline & 1 & $2215(24.9)$ \\
\hline & 2 & $2185(24.5)$ \\
\hline & 3 & $1580(17.7)$ \\
\hline & $4+$ & $1469(16.5)$ \\
\hline \multirow[t]{12}{*}{ History of comorbidity } & Atrial fibrillation & $1917(21.5)$ \\
\hline & Other arrhythmias & $1018(11.4)$ \\
\hline & Myocardial infarction & $484(5.4)$ \\
\hline & Coronary artery disease & $2274(25.5)$ \\
\hline & Myocarditis & $61(0.7)$ \\
\hline & Hypertension & $5235(58.7)$ \\
\hline & Stroke & $485(5.4)$ \\
\hline & Diabetes & $1773(19.9)$ \\
\hline & Congenital heart disease & $56(0.6)$ \\
\hline & Chronic pulmonary disease & $2034(22.8)$ \\
\hline & Peripheral vascular disease & $678(7.6)$ \\
\hline & Renal disease & $2010(22.6)$ \\
\hline \multirow[t]{4}{*}{ Symptom type } & Breathlessness only & $6176(69.3)$ \\
\hline & Ankle swelling only & $1202(13.5)$ \\
\hline & Fatigue only & $1412(15.8)$ \\
\hline & Two or more symptoms & $123(1.4)$ \\
\hline
\end{tabular}

IMD, Index of Multiple Deprivation.

\section{Time taken for NICE-recommended management}

Table 2 summarises waiting times in days from recorded symptom(s) to key elements of investigation and management. Timings are illustrated in figure 2 .

The median time from presentation with symptoms suggestive of HF to recorded investigations (serum NP test or echocardiogram) was 292 days (IQR 34-844), while the median time to specialist referral was 236 days (IQR 42-742). It took a median of 972 days for the diagnosis to be recorded (IQR 337-1468) and 803 days (IQR 230-1364) for relevant drug treatment (ACE inhibitor, ARB or HF-specific beta-blocker) to be started. All these varied significantly with patient factors.

There was no significant difference between men and women in waiting time for initial investigations, but women waited longer for referral (262 vs 210 days, $p=0.001)$, diagnosis (1052 vs 882 days, $\mathrm{p}<0.001)$ and medical treatment $(889$ vs 710 days, $\mathrm{p}<0.001)$. Age also had a significant impact on the speed at which patients received investigation and management, with those aged $65-74$ years waiting longest $(p<0.001)$. Higher deprivation score was similarly associated with increased delay in investigation $(p=0.003)$, referral $(p=0.001)$, diagnosis $(\mathrm{p}=0.001)$ and treatment $(\mathrm{p}<0.001)$.

Patients diagnosed during an acute admission to hospital waited less time for initial investigations $(\mathrm{p}<0.001)$, but the same time for referral. However, they waited almost twice as long for both diagnosis $(1091$ vs 653 days, $\mathrm{p}<0.001)$ and treatment $(916$ vs 509 days, $\mathrm{p}<0.001)$. Patients with the most $(4+)$ comorbidities were referred to a specialist most quickly. Patients with atrial fibrillation waited less time for investigation, referral, diagnosis and treatment $(\mathrm{p}<0.001)$, as did those with renal disease $(\mathrm{p}<0.005, \mathrm{n} / \mathrm{s}$ for treatment), while for patients with chronic pulmonary disease there was significant delay in all elements.

The large proportion of patients who presented with breathlessness only were investigated, referred, diagnosed and treated more quickly than those presenting with ankle swelling, fatigue or with a combination of symptoms $(p<0.001)$; those who presented with fatigue only had the longest waiting times $(\mathrm{p}<0.001)$.

For sensitivity analysis, we also considered a larger group of 15902 patients, including those with and without recorded symptoms, to examine median waiting times from investigation or referral to diagnosis and treatments with respect to whether patients were diagnosed in primary care or at acute hospital admission (table 3). As with our smaller cohort, those diagnosed in hospital experienced significantly longer waiting times from investigation or referral to diagnosis (561 vs 48 days, $\mathrm{p}<0.001$ ) and to medical treatment $(348 \mathrm{v} 31$ days, $\mathrm{p}<0.001)$.

\section{DISCUSSION}

\section{Summary of key findings}

Using nationally representative real-world data, we found that, of patients presenting in primary care with symptoms suggestive of HF, 39\% had a recorded NP or echocardiogram, and $36 \%$ a specialist referral. For symptomatic patients who had both investigation and referral to a specialist, median times from recorded symptom(s) to investigation and to referral were significantly longer than the recommended guidelines. The median time from symptom(s) to diagnosis was over two-and-a-half years (figure 2). Patients who were female, older, with higher deprivation score and presented only with fatigue all took significantly longer to achieve referral, diagnosis and treatment. Comorbid atrial fibrillation and renal disease appeared to speed up investigation and diagnosis, but patients with chronic pulmonary disease were subject to significantly longer delays for all elements of investigation and management. Patients tended to be treated earlier than they received their diagnosis, but median time from symptomatic presentation to treatment with HF medication was still over 2 years.

\section{Comparison with other studies}

We have previously reported, using CPRD, that few who presented with symptoms suggestive of HF followed a pathway aligned with NICE recommendations. ${ }^{13}$ This study expands on this, measuring the time taken for patients to achieve key elements of these recommendations, and considering the effect of various patient-related factors.

Part of the difficulty in the timely identification and diagnosis of patients with HF relates to the non-specific nature of the classic symptoms, which have been shown in other European studies to have considerable overlap with other conditions, especially in older adults. ${ }^{4}$ Patients with pre-existing respiratory conditions are particularly prone to delays in identification of $\mathrm{HF}^{9}$ and our study supports this, finding longer delays in 


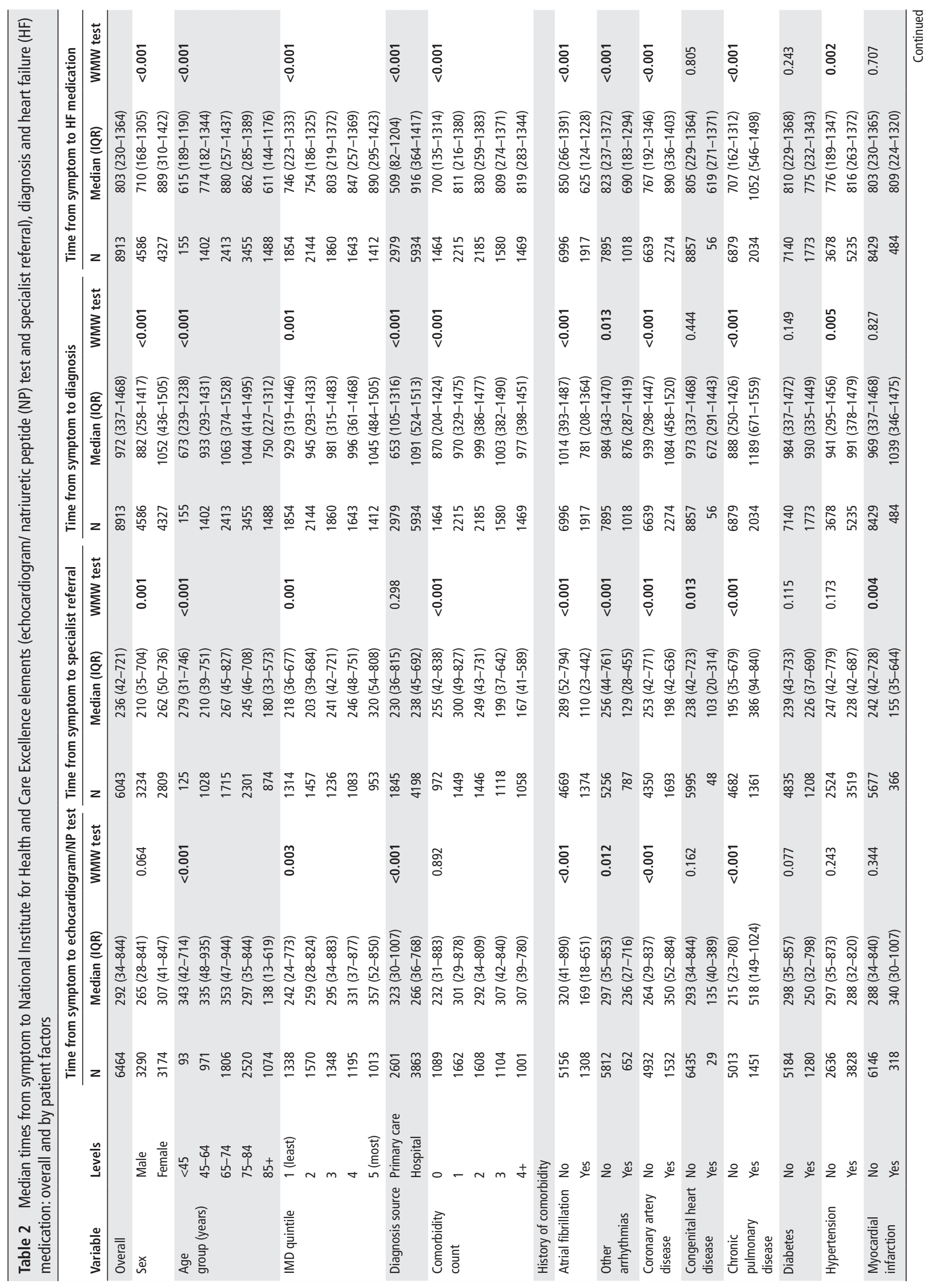




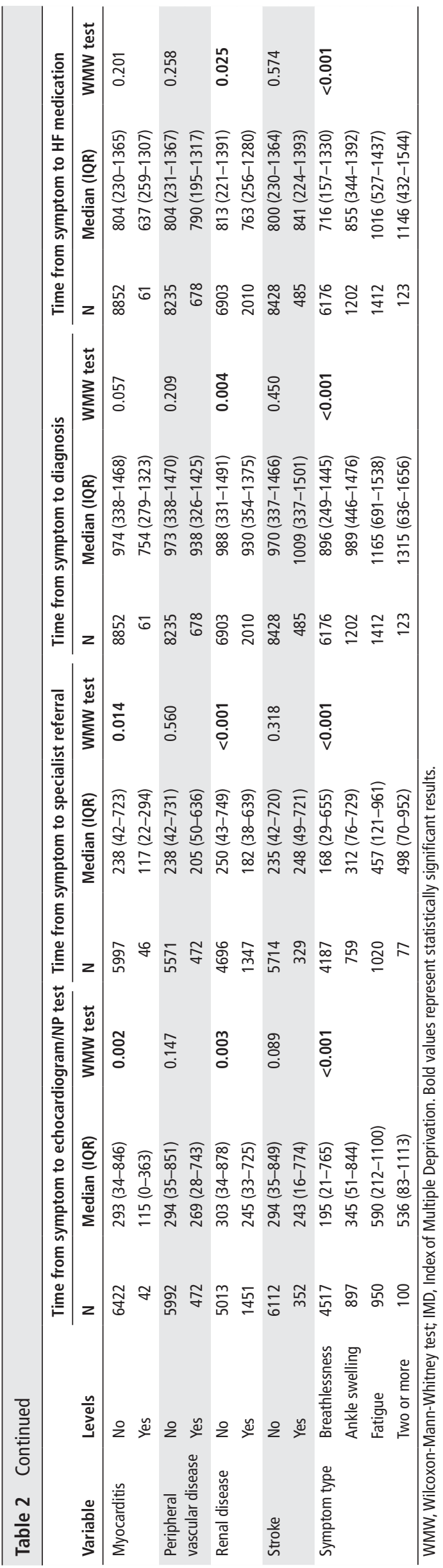

investigation, referral, diagnosis and treatment for those with chronic pulmonary disease.

We found evidence of significant age and sex differences in initial management and diagnosis of HF, with longer waiting times for female patients and for those in the age range of 65-74 years. The degree of diagnostic overlap may explain some of the difference in waiting times associated with age; younger patients with fewer comorbidities may be less subject to diagnostic confusion. Higher suspicion of HF in very old patients may explain the fall in waiting times in the oldest patients in our group. However, despite overall similar numbers of men and women living with HF in the developed world, older patients and women are significantly less likely to receive medical treatment for $\mathrm{HF}^{21}$; similar age and sex differences also exist in the diagnosis of other conditions including cancer. ${ }^{22}$

\section{Implications for policy and practice}

Earlier NICE guidance ${ }^{23}$ recommended use of ECG and/or NP testing to exclude HF in patients with suggestive symptoms, with echocardiography indicated in those where HF could not be excluded, and referral where there was diagnostic difficulty. Revised guidance in $2010^{11}$ focused on NP testing to exclude HF, before echocardiography and referral for all patients. This included clear recommendation for these to be completed within a specified time frame.

New evidence takes time to translate into practice, ${ }^{24}$ and clinicians may experience guideline overload. ${ }^{25}$ Inaccessibility of investigations such as NP testing and echocardiography is a significant problem in primary care, ${ }^{526}$ and long waiting lists for specialist assessment provide disincentive to referral..$^{25}$ Furthermore, $\mathrm{HF}$ can be a difficult diagnosis to make, ${ }^{25}$ with variable presentation, diagnostic overlap and symptoms that are not specific to HF. Nevertheless, a significant proportion of patients with HF in our study did have recorded symptoms, raising the possibility of missed opportunities for their earlier investigation, diagnosis and management.

The significantly longer wait for diagnosis and treatment of those diagnosed in hospital also suggests the existence of symptomatic untreated patients in primary care who eventually deteriorate to the extent that they attend an emergency department. Interestingly, these patients waited less time for investigations than those diagnosed in primary care. It is possible therefore that they either had normal initial investigations but were not followed up, or that they had investigations suggestive of HF but these were not acted on.

Further research is needed to understand how primary care professionals respond to patients presenting with symptoms suggestive of $\mathrm{HF}$ and the effect of their actions on patients; we plan further work investigating the impact of delays in the pathway of care on patients' likelihood of admission to hospital, morbidity and mortality. UK general practitioners are subject to significant workload pressures, ${ }^{27} 28$ and our findings provide further evidence for the need for increased funding and support for NHS primary care. It is essential that clinicians have the time and resources to investigate and manage patients effectively, with availability of key investigations for HF, including serum NP testing, ${ }^{26}$ and timely access to specialist assessment. The potential for diagnostic confusion with chronic pulmonary disease highlighted in our study may also support introduction of specialist breathlessness assessment services aimed at broader evaluation of patients with this symptom.

Finally, ACC/AHA guidelines refer to possible benefit in serum NP screening of patients at risk of HF (eg, those with 
Time taken from first symptom to NICE elements and diagnosis

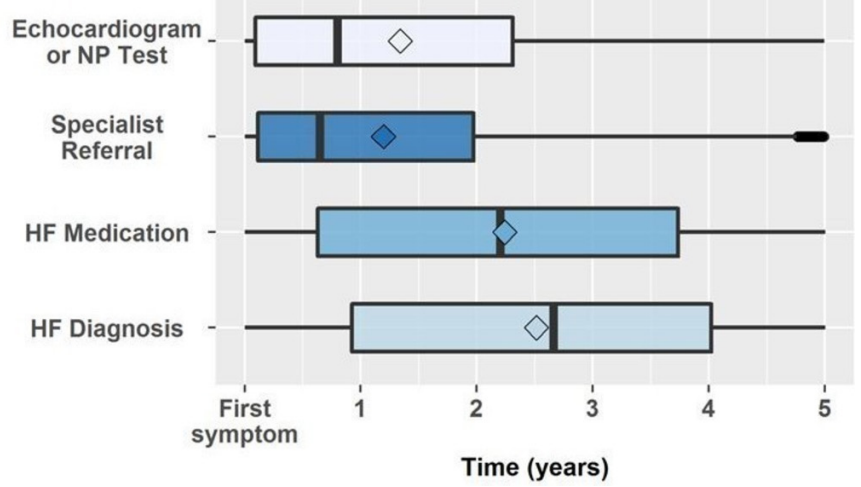

Figure 2 Timings from recorded symptom to investigation, referral and diagnosis. HF, heart failure; NICE, National Institute for Health and Care Excellence; NP, natriuretic peptide.

hypertension and diabetes), ${ }^{12} 29$ allowing targeted lifestyle interventions for those with higher NP results. This may be one way to address the frequent diagnostic delay suggested by our study. However, further research is needed to establish cost effectiveness and impact on quality of life and mortality of such an approach.

\section{Strengths and limitations}

CPRD is widely used in research ${ }^{30}$ and is representative of the UK population in age, sex and ethnicity. ${ }^{14}$ HES covers all NHS hospitals in England, with highly accurate coding of primary diagnoses. ${ }^{31}$ Linking these data sets allowed inclusion of HF diagnoses made both in primary care and during hospital admissions. Our study is limited to UK data, potentially reducing generalisability. However, difficulties in timely diagnosis and management of HF in primary care in other health settings ${ }^{46}$ suggest broader applicability, particularly to health systems where primary care acts as a gatekeeper to specialist services.

CPRD data are made up of clinical codes recorded by primary care professionals. Clinical coding in primary care is very variable, ${ }^{32}$ and it is probable that considerable relevant data are recorded either as free text or in letters from specialists, ${ }^{33}$ which are inaccessible to searches.

We included only patients with recorded symptoms. We have previously described lack of coding of HF symptoms, ${ }^{13}$ and we suspect clinicians are unlikely to record multiple symptom codes within a single consultation, making comparison of one or more symptoms less valid. Since 2006, the Quality and Outcomes Framework (QOF), a national primary care pay-for-performance scheme, has incentivised confirmation of HF by echocardiography or specialist assessment. ${ }^{34}$ Diagnostic codes, and those for investigations and referrals, may therefore be used more reliably than those for symptoms. QOF requires recording of this confirmation within 3 months before or 12 months after entry on the practice HF register. This may affect timing: professionals may be cautious in coding HF until confirmed. Recording of incentivised investigations and referrals may be similarly delayed.

The symptoms we considered are non-specific for HF; it is likely that some instances of breathlessness, for example, related to unconnected problems such as respiratory tract infections. We selected medications likely to be used in HF (ACE inhibitors, ARBs and HF-specific beta-blockers), but we had no way of identifying the specific indication of medications in our database: the prescriptions we identified could have been for conditions other than HF. Similarly, we assumed that referrals for echocardiography and cardiology assessment were made for suspected HF; of course both may be made for other cardiac concerns. For this reason, we excluded ECGs from our analysis, although recommended by NICE as part of the initial investigation of suspected HF: we felt that there were too many other potential reasons for requesting this test. In addition, although serum NP testing was recommended by ESC $^{35}$ in 2005 and NICE in $2003^{23}$ it was available for a minority of practices during our study period. ${ }^{5} 26$ Consequently, we combined NP testing with echocardiography in our analysis rather than examining them separately.

Finally, we searched for recorded diagnoses of HF until 31 March 2013. It is possible that greater familiarity of clinicians with guidance and increasing availability of investigations has resulted in improvements since this date.

\section{CONCLUSION}

Median times to investigation and referral of patients with symptoms suggestive of $\mathrm{HF}$ in primary care considerably exceeded those proposed by NICE, with waiting times in excess of 6 months the norm. Women, older people, those subject to higher deprivation, and those with chronic lung conditions were likely to wait longer still.

These findings do not explain the cause of delays in the pathway of care but suggest missed opportunities for more timely identification and management of HF. Future guidelines should focus on early investigation of suggestive symptoms and highlight the impact of patient factors to raise clinician awareness. Consideration should also be given to screening of asymptomatic individuals using serum NP testing. Increased monitoring of the implementation of guidance may encourage early uptake of innovation. ${ }^{36}$ However, primary care clinicians must be adequately supported, with availability of key investigations and timely access to specialist assessment both essential if the diagnosis of patients with HF is to be made more rapidly than at present. $^{26}$

Table 3 Median times from the National Institute for Health and Care Excellence (NICE) elements (echocardiogram/ natriuretic peptide (NP) test/ specialist referral) to diagnosis and heart failure (HF) medication: overall and by diagnosis source

\begin{tabular}{|c|c|c|c|c|c|c|c|}
\hline \multirow[b]{2}{*}{ Variable } & \multirow[b]{2}{*}{ Level } & \multicolumn{3}{|c|}{$\begin{array}{l}\text { Time from echocardiogram/NP test/specialist referral to } \\
\text { diagnosis }\end{array}$} & \multicolumn{3}{|c|}{$\begin{array}{l}\text { Time from echocardiogram/NP test/specialist referral to } \mathrm{HF} \\
\text { medication }\end{array}$} \\
\hline & & $\mathrm{N}$ & Median (IQR) & WMW test & $\mathrm{N}$ & Median (IQR) & WMW test \\
\hline Overall & & 15902 & 348 (37-1017) & & 15902 & $172(17-791)$ & \\
\hline \multirow[t]{2}{*}{ Diagnosis source } & Primary care & 4957 & 48 (4-399) & & 4957 & $31(1-210)$ & \\
\hline & Hospital & 10945 & 561 (123-1166) & $<0.001$ & 10945 & $348(43-960)$ & $<0.001$ \\
\hline
\end{tabular}




\section{Key questions}

\section{What is already known about this subject?}

- Timely diagnosis and treatment of heart failure (HF) is essential to its effective management, but identification remains difficult, especially in primary care where many patients present.

- For those patients that follow a pathway to HF diagnosis supported by the National Institute for Health and Care Excellence (NICE) guidance in primary care, the extent to which investigation and specialist referral takes place within recommended time limits is unclear.

\section{What might this study add?}

- We demonstrate that median times from presentation with symptoms suggestive of HF in primary care to investigation or referral exceed those recommended by NICE (2-6 weeks) by a considerable margin, exceeding 6 months for most patients.

- Median time from presentation with symptoms suggestive of HF to recorded relevant investigations was 292 days (IQR 34-844) and to specialist referral was 236 days (IQR 42-742).

\section{How might this impact on clinical practice?}

- These findings do not explain the cause of delays in the pathway of care but suggest missed opportunities for timely diagnosis and management of HF in primary care.

- There is clearly a need for further support for primary care clinicians in its earlier identification, with availability of key investigations and timely access to specialist assessment essential.

Contributors $B H, D K$ and $A B$ conceived and designed the study. $A B$ and $D K$ prepared the data; DK carried out the analysis, overseen by $A B$ and $B$ H. All authors took part in interpreting the data for this study. All authors commented on and helped to revise drafts of this paper. All authors have approved the final version. $\mathrm{BH}$ is the guarantor.

Funding This work was partly supported by Dr Foster®, a private healthcare information company, via a research grant to the Dr Foster Unit at Imperial College London. The Dr Foster Unit at Imperial College London is also partly funded by research grants from the National Institute for Health Research (NIHR) including the Imperial Patient Safety Translational Research Centre. Prof Cowie's salary is supported by the NIHR Cardiovascular Biomedical Research Unit at the Royal Brompton Hospital, London. This research was also supported by the National Institute for Health Research Collaboration for Leadership in Applied Health Research and Care Northwest London (NIHR CLAHRC NWL).

Disclaimer The views expressed in this article are those of the author(s) and not necessarily those of the NHS, the NIHR or the Department of Health and Social Care.

Competing interests $\mathrm{BH}$ and $\mathrm{AM}$ are both general practitioners, and $\mathrm{MC}$ a consultant cardiologist, working in the NHS.

\section{Patient consent Not required.}

Ethics approval We have approval from the Secretary of State and the Health Research Authority under Regulation 5 of the Health Service (Control of Patient Information) Regulations 2002 to hold confidential data and analyse them for research purposes (CAG ref 15/CAG/0005). We have approval to use them for research and measuring quality of delivery of healthcare, from the London - South East Ethics Committee (REC ref 15/LO/0824). The CPRD Group has obtained ethical approval from a National Research Ethics Service Committee (NRES) for all purely observational research using anonymised CPRD data. This study has been carried out as part of the work approved by their Independent Scientific Advisory Committee (ISAC) with protocol number 16_003RAR.

Provenance and peer review Not commissioned; externally peer reviewed.

Data sharing statement Due to information governance rules applicable to CPRD, no data are available for sharing.

\section{REFERENCES}

1 Ponikowski P, Voors AA, Anker SD, et al. 2016 ESC Guidelines for the diagnosis and treatment of acute and chronic heart failure: The Task Force for the diagnosis and treatment of acute and chronic heart failure of the European Society of Cardiology (ESC)Developed with the special contribution of the Heart Failure Association (HFA) of the ESC. Eur Heart J 2016;37:2129-200.

2 Ponikowski P, Anker SD, AlHabib KF, et al. Heart failure: preventing disease and death worldwide. ESC Heart Fail 2014;1:4-25.

3 Hobbs FDR, Doust J, Mant J, et al. Diagnosis of heart failure in primary care. Heart 2010;96:1773-7.

4 van Riet EE, Hoes AW, Limburg A, et al. Prevalence of unrecognized heart failure in older persons with shortness of breath on exertion. Eur J Heart Fail 2014;16:772-7.

5 Hancock HC, Close H, Fuat A, et al. Barriers to accurate diagnosis and effective management of heart failure have not changed in the past 10 years: a qualitative study and national survey. BMJ Open 2014;4:e003866.

6 Dahlstrom U, Hakansson J, Swedberg K, et al. Adequacy of diagnosis and treatment of chronic heart failure in primary health care in Sweden. Eur J Heart Fail 2009;11:92-8.

7 Mejhert M, Kahan T. A management programme for suspected heart failure in primary care in cooperation with specialists in cardiology. Eur J Gen Pract 2015;21:26-32.

8 Mosterd A, Hoes AW. Clinical epidemiology of heart failure. Heart 2007;93:1137-46.

9 Rutten FH, Moons KG, Cramer MJ, et al. Recognising heart failure in elderly patients with stable chronic obstructive pulmonary disease in primary care: cross sectional diagnostic study. BMJ 2005;331:1379-0.

10 Ahn SA, Jong P, Yusuf S, et al. Early versus delayed enalapril in patients with left ventricular systolic dysfunction: impact on morbidity and mortality 15 years after the SOLVD trial. J Am Coll Cardiol 2006:47:1904-5.

11 National Institute of Health and Care Excellence. Chronic heart failure: national clinical guideline for diagnosis and management in primary and secondary care: National Clinical Guideline Centre, 2010.

12 Yancy CW, Jessup M, Bozkurt B, et al. 2017 ACC/AHA/HFSA Focused Update of the 2013 ACCF/AHA Guideline for the Management of Heart Failure: a report of the American College of Cardiology/American Heart Association Task Force on Clinical Practice Guidelines and the Heart Failure Society of America. Circulation 2017;136:e137-61.

13 Bottle A, Kim D, Aylin P, et al. Routes to diagnosis of heart failure: observational study using linked data in England. Heart 2018;104:600-5.

14 Herrett E, Gallagher AM, Bhaskaran K, et al. Data resource profile: clinical practice research datalink (CPRD). Int J Epidemiol 2015;44:827-36.

15 Hawkins NM, Scholes S, Bajekal M, et al. Community care in England: reducing socioeconomic inequalities in heart failure. Circulation 2012;126:1050-7.

16 World Health Organization. The international classification of diseases and related health problems, 10th revision. $2016 \mathrm{http}: / /$ apps.who.int/classifications/icd10/browse/ 2016/en (cited 23 Apr 2018).

17 Ministry of Housing, Communities and Local Government. Index of multiple deprivation score, 2010 [Internet]. Open Data Communities. 2013 http:// opendatacommunities.org/data/societal-wellbeing/deprivation/imd-score-2010 (cited 23 Apr 2018).

18 Khan NF, Perera R, Harper S, et al. Adaptation and validation of the Charlson Index for Read/OXMIS coded databases. BMC Fam Pract 2010;11:1.

19 NHS England. Business Rules for Quality and Outcomes Framework (QOF) 2017/18: Heart failure. [Internet]. NHS Digital. 2017 https://digital.nhs.uk/data-and-information/ data-collections-and-data-sets/data-collections/quality-and-outcomes-framework-qof/ quality-and-outcome-framework-qof-business-rules/quality-and-outcomes-framework qof-business-rules-v37-0/heart-failure-v37-0-qof-business-rules-2017-18 (cited 23 Sep 2018).

20 Stocks SJ, Kontopantelis E, Akbarov A, et al. Examining variations in prescribing safety in UK general practice: cross sectional study using the Clinical Practice Research Datalink. BMJ 2015;351:h5501.

21 Mehta PA, Cowie MR. Gender and heart failure: a population perspective. Heart 2006;92(Suppl 3):iii14-18.

22 Din NU, Ukoumunne OC, Rubin G, et al. Age and gender variations in cancer diagnostic intervals in 15 cancers: analysis of data from the UK Clinical Practice Research Datalink. PLoS One 2015;10:e0127717.

23 National Collaborating Centre for Chronic Conditions (UK). Chronic Heart Failure: National Clinical Guideline for Diagnosis and Management in Primary and Secondary Care. 2003 https://www.ncbi.nlm.nih.gov/books/NBK65603/.

24 Lau R, Stevenson F, Ong BN, et al. Achieving change in primary care--causes of the evidence to practice gap: systematic reviews of reviews. Implement Sci 2016;11:40.

25 Smeets M, Van Roy S, Aertgeerts B, et al. Improving care for heart failure patients in primary care, GPs' perceptions: a qualitative evidence synthesis. BMJ Open 2016;6:e013459

26 All Party Parliamentary Group on Heart Desease. Focus on heart failure: 10 recommendations to improve care and tranform lives [Internet]. London: British Heart Foundation, 2016.

27 RCGP. Patient safety implications of general practice workload [Internet]. 2015 http:// www.rcgp.org.uk/policy/rcgp-policy-areas/ /media/Files/Policy/A-Z-policy/2015/ 
RCGP-Patient-safety-implications-of-general-practice-workload-July-2015.ashx (cited 5 May 2017).

28 Hobbs FDR, Bankhead C, Mukhtar T, et al. Clinical workload in UK primary care: a retrospective analysis of 100 million consultations in England, 2007-14. The Lancet 2016;387:2323-30.

29 Ledwidge M, Gallagher J, Conlon C, et al. Natriuretic peptide-based screening and collaborative care for heart failure: the STOP-HF randomized trial. JAMA 2013;310:66.

30 Chaudhry Z, Mannan F, Gibson-White A, et al. Outputs and Growth of Primary Care Databases in the United Kingdom: Bibliometric Analysis. J Innov Health Inform 2017;24:284

31 Burns EM, Rigby E, Mamidanna R, et al. Systematic review of discharge coding accuracy. J Public Health 2012;34:138-48.
32 Jordan K, Porcheret M, Croft P. Quality of morbidity coding in general practice computerized medical records: a systematic review. Fam Pract 2004;21:396-412.

33 Ford E, Carroll J, Smith $\mathrm{H}$, et al. What evidence is there for a delay in diagnostic coding of RA in UK general practice records? An observational study of free text. BMJ Open 2016;6: 010393.

34 Deaton C, Benson J. Time for correct diagnosis and categorisation of heart failure in primary care. Br J Gen Pract 2016;66:554-5.

35 Swedberg K, Cleland J, Dargie H, et al. Guidelines for the diagnosis and treatment of chronic heart failure: executive summary (update 2005). Eur Heart J 2005;26:1115-40

36 Taylor H. Accelerated access review: final report [Internet]. London: Wellcome Trust, 2016. 